\title{
MARINE DIESEL HIGH PRESSURE FUEL PUMP DRIVING FAILURE ANALYSIS
}

\author{
PROTSENKO Vladyslav', BABIY Mykhaylo², \\ NASTASENKO Valentyn ${ }^{3}$, PROTASOV Roman ${ }^{4}$ \\ ${ }^{l}$ Faculty of Marine Engineering, Kherson State Maritime Academy, Ushakov ave., 20, 73003, \\ Kherson, Ukraine, e-mail: 1904pvo@gmail.com \\ ${ }^{2}$ Faculty of Marine Engineering, Kherson State Maritime Academy, Ushakov ave., 20, 73003, \\ Kherson,Ukraine, e-mail: m_babiy@ukr.net \\ ${ }^{3}$ Faculty of Marine Engineering, Kherson State Maritime Academy, Ushakov ave., 20, 73003, \\ Kherson, Ukraine, e-mail: nastasenko2004@ukr.net \\ ${ }^{4}$ Slovak University of Technology in Bratislava, Faculty of Mechanical Engineering, Institute of transport \\ technology and designing, Nám. Slobody 17,812 31 Bratislava, \\ Slovakia, e-mail: roman.protasov@stuba.sk
}

\begin{abstract}
The structure of the MAK M43 diesel high pressure fuel pump driving is analyzed. It is shown that presence of redundant constraints in its mechanism is the reason of roller bearings failure. It is proposed redundant constraints elimination by adding movabilities in mechanism.
\end{abstract}

KEYWORDS: self-aligning mechanism; redundant constraints; marine diesel; high pressure fuel pump.

\section{Introduction}

Plenty of the marine machine parts failures have its reason of uneven load distribution between them. This occurrence is often associated with redundant constraints presence in the mechanisms of these machines [10]. Their influence is often offset by the inflated accuracy of details manufacture, the performance of fitting operations during assembling, which leads to increase capital and operating costs. Sometimes the impact of redundant constraints occurs after repairs, which are usually accompanied by errors of surfaces shape and location due to low accuracy of tooling and assembling [1, 13]. Methods for finding and eliminating redundant constraints is the basis for creating rational machine designs and reducing capital costs. Detection links loads and elimination of redundant constraints are considered for the mechanisms of railway transport [10], metallurgical $[3,9,17]$, robot mechanisms $[11,12]$ and technological machines [16]. The elimination of redundant constraints in the marine diesels mechanisms is especially acute, because they contain multi-supported shafts, links which are intaking in several kinematic pairs. For marine engines, these issues are studied insufficiently and in the textbooks used for the marine engineers study $[2,4,8]$ are practically not covered. Although detecting redundant constraints is a reserve for reducing capital and operating costs for marine diesels.

\section{Methodology}

\section{Mechanism design and construction.}

Marine diesel MaK43 plunger-type high pressure fuel injection pump driving (fig. 1, fig. 2) contains five $(n=5)$ movable links ( 1 - cam, 2 - roller, 3 - follower, 4 - pusher, 5 - plunger). Plunger 5 and plunger bushing form 5 -class kinematic pair $F_{5}$. Plunger 5 and follower 3 
connected with pusher 4 by spherical 3-class joints $D_{3}$ and $E_{3}$. Roller 2 connected with cam 1 by 3-class joint $A_{3}$. Follower 3 and cam 1 connected with engine block by 5 -class pairs $O_{5}$ and B5.

\section{Parts failures.}

Rollers bearings bushings destruction which took place in practice are depicted on fig. 3 . Bushings destruction were local, their area was unevenly distributed along the length. The zone of the greatest destruction was near one of the ends of the bushings, and their angular length reached $170 \ldots 180^{\circ}$, this zone did not reach the other bushing end. This indicates the presence of load concentration due to the angular misalignment of roller and cam axes.

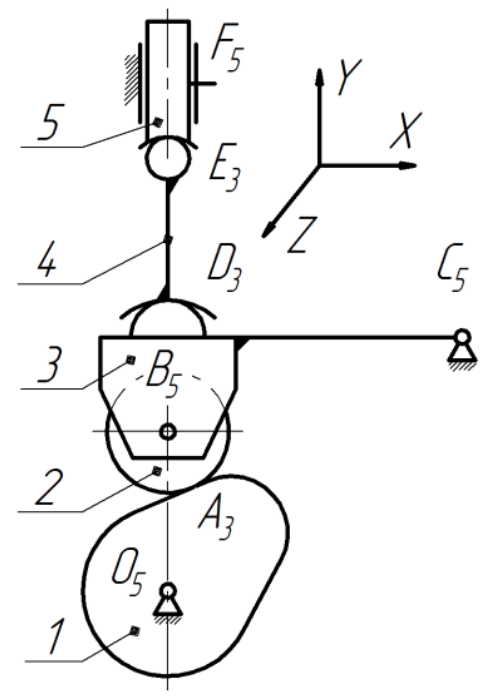

Fig. 1 Structural diagram of plungertype high pressure fuel injection pump driving mechanism

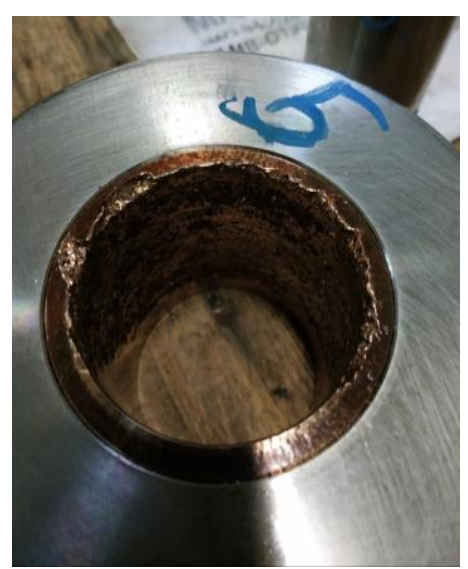

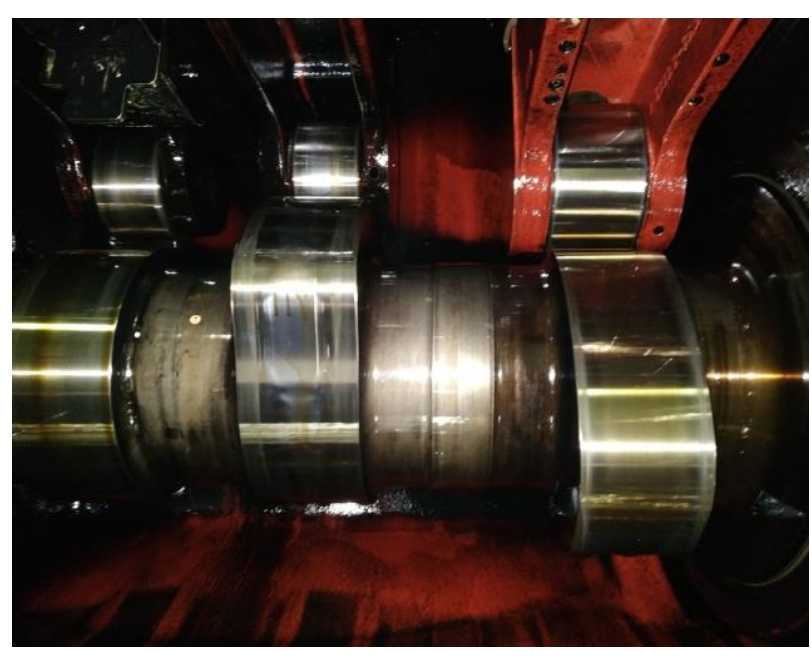

Fig. 2 Photograph of plunger-type high pressure fuel injection pump driving mechanism main elements

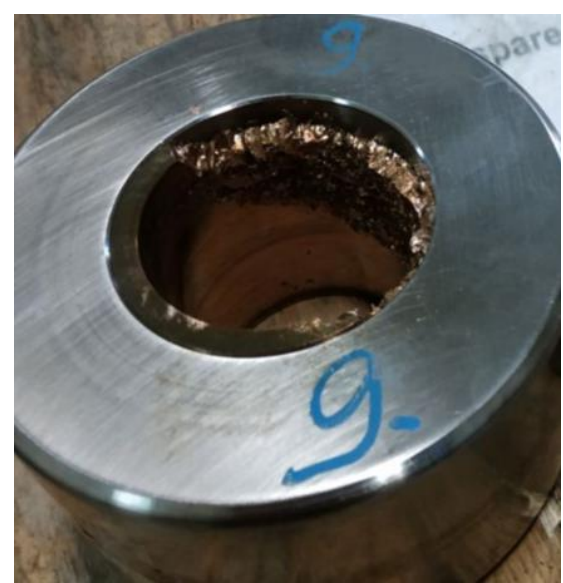

Fig. 3 Photographs of failed rollers with destructed bearings bushings (from cylinders 5 and 9)

\section{Causes of failure.}

For described mechanism number of movable links is five $(n=5)$. Number of 5-class kinematic pairs here is $P_{5}=4\left(O_{5}, B_{5}, C_{5}, F_{5}\right)$, number of 3-class kinematic pairs is $P_{3}=3\left(A_{3}\right.$, $\left.D_{3}, E_{3}\right)$, pairs of fourth, second and first class are absent $\left(P_{4}=P_{2}=P_{1}=0\right)$.

Total kinematic pairs number is:

$$
P=P_{5}+P_{4}+P_{3}+P_{2}+P_{1}=4+0+3+0+0=7 .
$$


The sum of kinematic pairs movabilities:

$$
f=1 P_{5}+2 P_{4}+3 P_{3}+4 P_{2}+5 P_{1}=1 \times 4+2 \times 0+3 \times 3+4 \times 0+5 \times 0=13 .
$$

Number of independent locked circuits by Gohman formula [5]:

$$
k=P-n=7-5=2 \text {. }
$$

First independent locked circuit in driving mechanism $-C_{5} B_{5} A_{3} O_{5} C_{5}$, second one $C_{5} D_{3} E_{3} F_{5} C_{5}$.

Total mechanism mobility in basic variant [15]:

$$
W=f-\sum r_{i}=13-(4+6)=3,
$$

where $r_{1}=4$ - independent locked circuit $C_{5} B_{5} A_{3} O_{5} C_{5}$ kinematic pairs axes rank; $r_{2}=6-$ independent locked circuit $C_{5} D_{3} E_{3} F_{5} C_{5}$ kinematic pairs axes rank.

$$
W=W_{b}+W_{l}=1+2=3 \text {, }
$$

where $W_{b}=1$ - basic mechanism mobility; $W_{l}=2$ - local links 2 and 4 mobility (rotation around $Y$ and $Z$ axes respectively).

Therefore redundant constraints number in basic variant by Somov and Malyshev formula [6]:

$$
\begin{aligned}
& q_{S M}=W+5 P_{5}+4 P_{4}+3 P_{3}+2 P_{2}+P_{1}-6 n= \\
& =3+5 \times 4+4 \times 0+3 \times 3+2 \times 0+0-6 \times 5=2 ;
\end{aligned}
$$

Redundant constraints number by Ozols formula [7]:

$$
q_{O Z}=W+6 k-f=3+6 \times 2-13=2 .
$$

Circuit method confirms given results and allows to specify redundant constraints type and location (table 1) - all of them located in $\mathrm{C}_{5} B_{5} A_{3} \mathrm{O}_{5} \mathrm{C}_{5}$ circuit. The mechanism self-aligning makes impossible absence in kinematic pairs of two degrees - movabilities around $X$ and $Y$ axes $\left(f_{x}^{\prime \prime}, f_{y}^{\prime \prime}\right)$. Therefore, redundant constraints exclusion requires addition to $C_{5} B_{5} A_{3} O_{5} C_{5}$ circuit two absent movabilities through available kinematic pairs class raise.

\section{Results and discussion}

\section{Failure elimination measures}

First way of redundant constraints exclusion is roller external surface modifying to make it barrel-shaped (variant $I$ ). Through this kinematic pair $A$ class will raise from third to first, adding this way necessary movabilities without links number increasing. Mechanism

\begin{tabular}{|c|c|c|}
\hline \multirow[b]{2}{*}{ Circuit } & Planar movabilities $f_{n}$ & \multirow{4}{*}{$\begin{array}{lll}f_{x}^{\prime \prime} & f_{y}^{\prime \prime} & f_{z}^{\prime} \\
\varnothing & \varnothing & A \\
\downarrow_{q_{1}} & \downarrow_{q_{2}} \\
& & \stackrel{+}{w_{l}(5)} \\
D E & D E & \varnothing\end{array}$} \\
\hline & \multirow{3}{*}{ 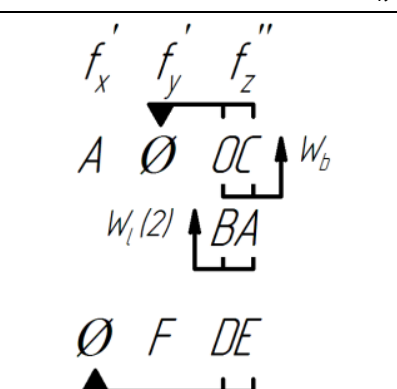 } & \\
\hline$C_{5} B_{5} A_{3} O_{5} C_{5}$ & & \\
\hline$C_{5} D_{3} E_{3} F_{5} C_{5}$ & & \\
\hline
\end{tabular}
structural diagram for this variant is depicted on fig. 4 . In the case of described roller surface modifying, 5-class kinematic pairs number became $P_{5}=4\left(\mathrm{O}_{5}, \mathrm{~B}_{5}, \mathrm{C}_{5}, \mathrm{~F}_{5}\right)$, 4-class and 2-class kinematic pairs $P_{4}=P_{2}=0,3$-class kinematic pairs $P_{3}=2\left(D_{3}, E_{3}\right)$, 1-class kinematic pair $P_{l}=1\left(A_{1}\right)$

Table 1 Circuit method application to high-pressure fuel pump driving mechanism in basic variant 
Then sum of kinematic pairs movabilities:

$$
f=1 P_{5}+2 P_{4}+3 P_{3}+4 P_{2}+5 P_{1}=1 \times 4+2 \times 0+3 \times 2+4 \times 0+5 \times 1=15 .
$$

Total mechanism mobility in new variant $I$ :

$$
W=f-\sum r_{i}=15-(6+6)=3,
$$

where $r_{1}=6$ - independent locked circuit $C_{5} B_{5} A_{3} O_{5} C_{5}$ kinematic pairs axes rank in new variant $I$.

Redundant constraints number in new variant $I$ :

$$
\begin{gathered}
q_{S M}=W+5 P_{5}+4 P_{4}+3 P_{3}+2 P_{2}+P_{1}-6 n=3+5 \times 4+4 \times 0+3 \times 2+2 \times 0+1-6 \times 5=0, \\
q_{O Z}=W+6 k-f=3+6 \times 2-15=0 .
\end{gathered}
$$

\begin{tabular}{|c|c|c|}
\hline \multirow[b]{2}{*}{ Circuit } & Planar movabilities $f_{p}$ & Non-planar movabilities $f_{n}$ \\
\hline & \multirow{3}{*}{$\begin{array}{lll}f_{x}^{\prime} & f_{y}^{\prime} & f_{z}^{\prime \prime} \\
A & \varnothing & O C \\
w_{l}(2) & \stackrel{B A}{B A} \\
\varnothing & F & D E\end{array}$} & \multirow{2}{*}{$\begin{array}{lll}f_{x}^{\prime \prime} & f_{y}^{\prime \prime} & f_{z}^{\prime} \\
A & A & A\end{array}$} \\
\hline$C_{5} B_{5} A_{1} O_{5} C_{5}$ & & \\
\hline$C_{5} D_{3} E_{3} F_{5} C_{5}$ & & $\underset{\mathbf{L}}{D E} \overline{D E} \varnothing$ \\
\hline
\end{tabular}

Circuit method application is given in table 2, confirms calculation results for variant $I$.

Table 2 Circuit method application to high-pressure fuel pump driving mechanism in new variant $I$

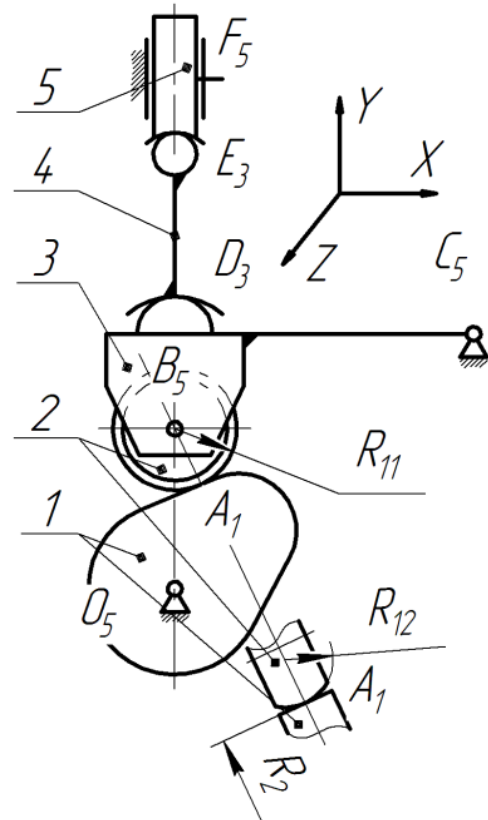

Fig. 4 Structural diagram of plunger-type high pressure fuel injection pump driving mechanism in proposed variant $I$

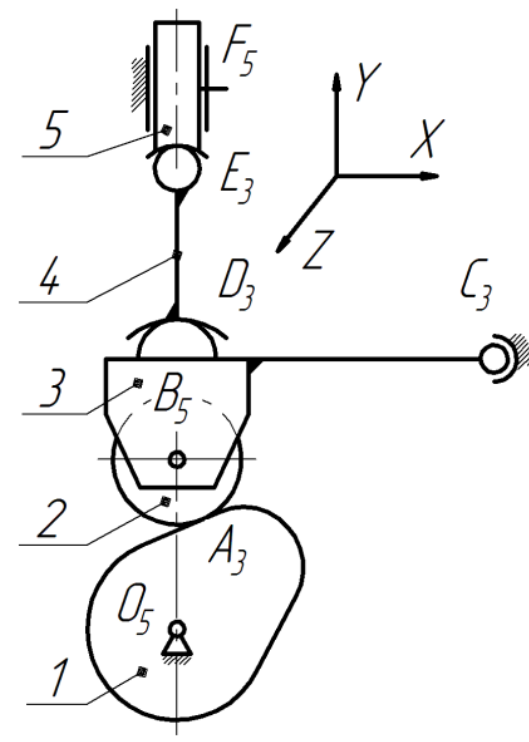

Fig. 5 Structural diagram of plunger-type high pressure fuel injection pump driving mechanism in proposed variant $I I$

$$
W=3, q=0
$$

Similar reserve for redundant constraints elimination could gives kinematic pair $C$ spherical making (variant $I I$ ). In this way its class became third from fifth. In this case (fig. 5) each class kinematic pairs number became: $P_{5}=3\left(O_{5}, B_{5}, F_{5}\right), P_{4}=P_{2}=P_{1}=0, P_{3}=4\left(A_{3}\right.$, 
$\left.C_{5}, D_{3}, E_{3}\right)$. Total kinematic pairs movabilities and mechanism mobilities number will be equal to variant $I$.

Redundant constraints number in new variant $I I$ :

$$
\begin{gathered}
q_{S M}=W+5 P_{5}+4 P_{4}+3 P_{3}+2 P_{2}+P_{1}-6 n=3+5 \times 3+4 \times 0+3 \times 4+2 \times 0+0-6 \times 5=0, \\
q_{O Z}=W+6 k-f=3+6 \times 2-15=0 .
\end{gathered}
$$

Circuit method application for variant $I I$ is given in table 3 .

Both of proposed variants in roller and cam angular misalignment $\chi$ condition could provide roller self-aligning on cam and ensure even load distribution along the roller bearing length (fig. 6, b) compared with basic cylindrical roller and follower joint (fig. 6, a).

Table 3 Circuit method application to high-pressure fuel pump driving mechanism in new

\begin{tabular}{|c|c|c|}
\hline \multirow[b]{2}{*}{ Circuit } & Planar movabilities $f_{p}$ & \multirow{3}{*}{ 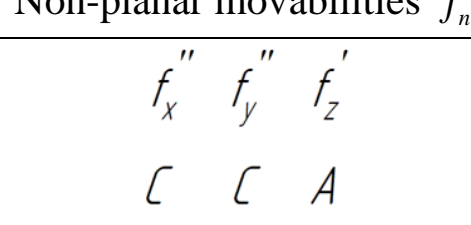 } \\
\hline & \multirow{3}{*}{ 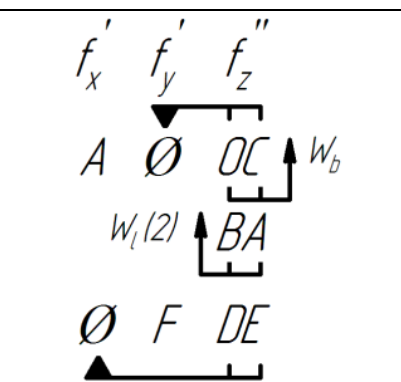 } & \\
\hline$C_{5} B_{5} A_{3} O_{5} C_{5}$ & & \\
\hline$C_{5} D_{3} E_{3} F_{5} C_{5}$ & & DE DE Ø \\
\hline & $W=3, q$ & \\
\hline
\end{tabular}
variant $I I$

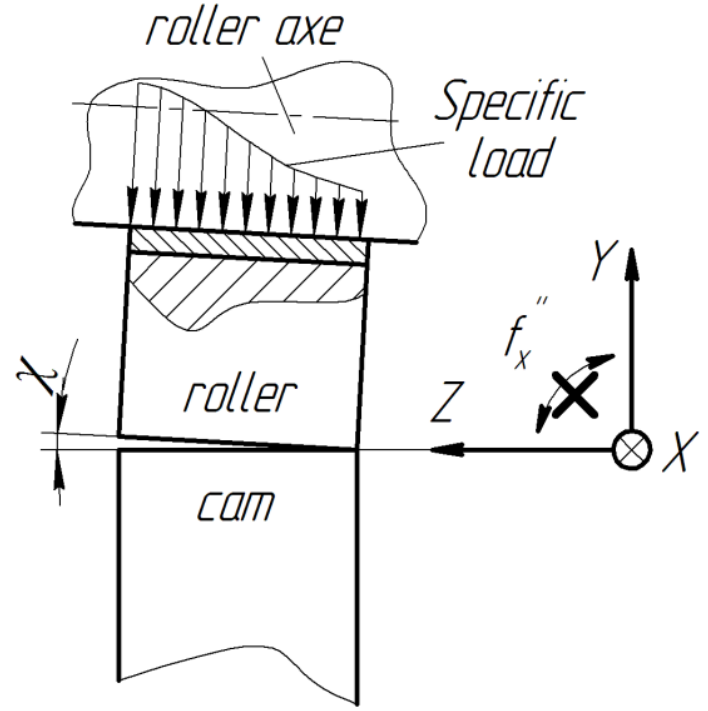

a)

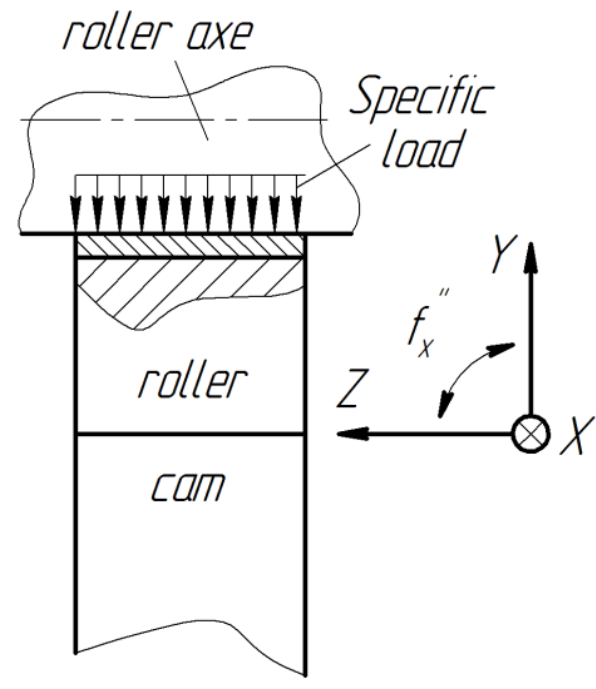

b)

Fig. 6 Roller bearing load distribution diagram in the cylindrical (a) and spherical rollerfollower connection (b) in angular misalignment $\chi$ condition

Variant $I I$ could use in new designing engine constructions because it requires a change the follower design and the technology of its manufacturing. 
The possibility of using variant $I$ for the modernization of diesels in operation illustrated by pair "cam-roller" contact stresses $\sigma_{H}$ [14] calculation in the case of roller barrel-shaped surface:

$$
\sigma_{H}=\frac{0,478 F^{1 / 3}}{\alpha \beta\left[\frac{3\left(1-\mu^{2}\right)}{E\left(1 / R_{11}+1 / R_{12}+1 / R_{2}\right)}\right]^{2 / 3}},
$$

where $F$ - roller radial load; $\mu$ - Poisson ratio; $E$ - consolidated tangent modulus for roller and cam materials; $R_{11}$ and $R_{12}$ - roller external surface radiuses in longitudinal and cross sections (fig. 13); $R_{2}$ - cam external surface radius; $\alpha, \beta$ - coefficients.

$$
\begin{aligned}
& \alpha=62,19 \psi^{-0,9143} ; \\
& \beta=0,3559 e^{0,0116 \psi},
\end{aligned}
$$

Auxiliary angle $\psi$ calculate as:

$$
\cos \psi=\frac{\sqrt{\left(1 / R_{11}-1 / R_{12}\right)^{2}+1 / R_{2}^{2}+2\left(1 / R_{11}-1 / R_{12}\right) / R_{2}^{2}}}{1 / R_{11}+1 / R_{12}+1 / R_{2}} .
$$

Measured on engine directly: $R_{11}=65 \mathrm{MM}, R_{2}=40 \mathrm{MM}$, calculated $F \approx 72500 N$ (fuel injection valve opening pressure $47 \mathrm{MPa}$ ), $\mu=0,3$; $E=2,12 \times 10^{5} \mathrm{MPa}$ (both of roller and cam are made from steel). Calculation results are depicted in fig. 7 in coordinates $K-S\left(K=R_{12} / R_{11}\right.$ - radiuses ratio; $S=\left[\sigma_{\mathrm{H}}\right] / \sigma_{\mathrm{H}}-$ safety coefficient, $\left[\sigma_{\mathrm{H}}\right]=2500 \mathrm{MPa}$ - permissible contact stress. The graph on fig. 7 proves the possibility of achieving acceptable values of contact stresses at the $K$ ratio at the level $K>10$.

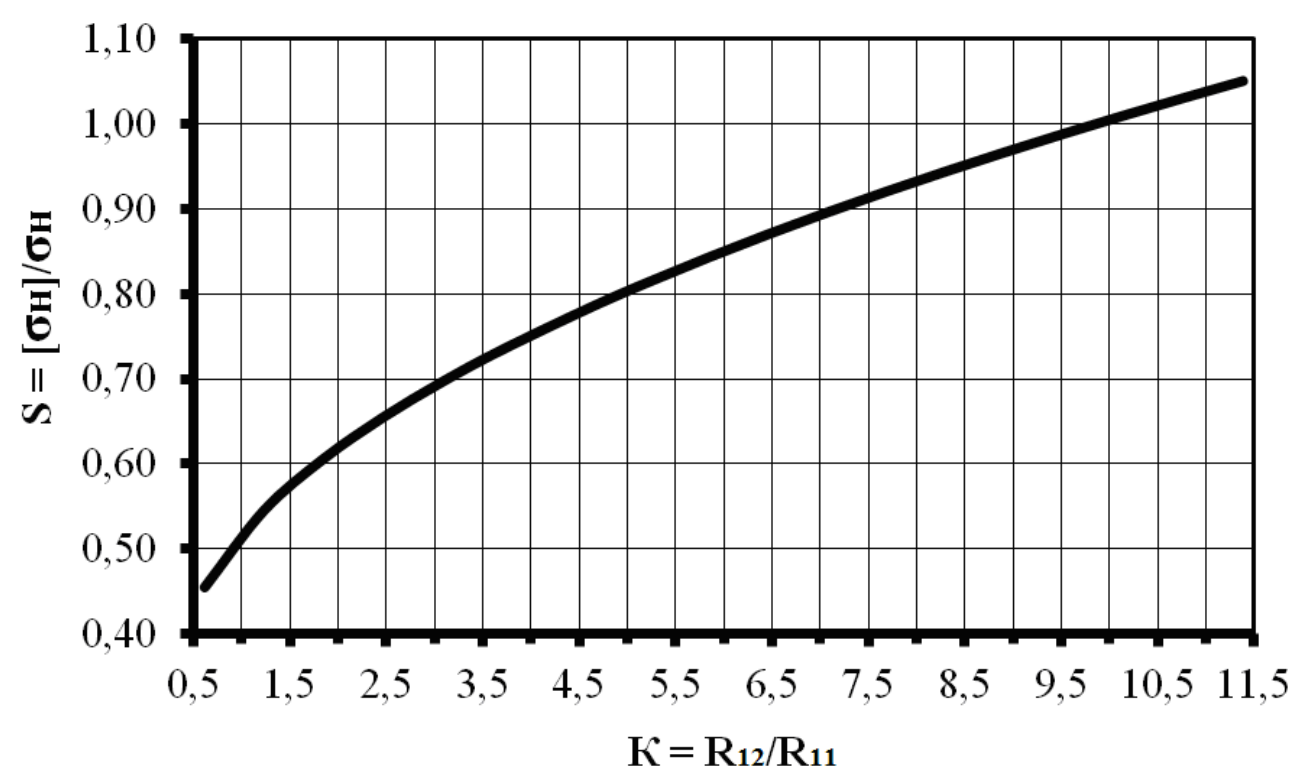

Fig. 7 Graph of the contact stresses in the pair "roller-cam" dependence of roller external working surface radiuses ratio

\section{CONCLUSION}

It is shown that described failure could eliminate by made high pressure pump driving mechanism self-aligning. This could realize by one of two variants: making roller external 
surface barrel-shaped (variant I), or using spherical joint for follower and diesel block connection (variant II). Both of the variants could exclude redundant constraints in mechanism. Variant I can use on engines in operation, variant II - for new-designing diesel engines.

\section{REFERENCES}

[1] Atarer, F., Korkmaz, K., Kiper, G. "Design alternatives of network of Altmann linkages", International Journal of Computational Methods and Experimental Measurements 5 (4), pp. 495 - 503, 2017. DOI: 10.2495/CMEM-V5-N4495-503

[2] Bulgakov, V. M., Yaremenko, V. V., Chernysh, O. M. "Applied mechanics", Kyiv: CNL. 2020.

[3] Gudimova, L.N. "Improvement of construction of a press actuator", Chernye Metally. 6, pp. 39 - 44, 2019.

[4] Gulida, E. M., Dzyba, L. F., Olkhoviy, I. M. “Applied mechanics”, Lviv: Svit, 2007.

[5] Kolovsky, M. Z., Evgrafov, A. N., Semenov, Yu. A. et al. 2000. Advanced theory of mechanisms and machines. Berlin: Springer.

[6] Mata, S. A., Torras, A. B., Cabrera, J. A. et al. "Fundamentals of Machine Theory and Mechanisms", Cham: Springer, 2016.

[7] Ozols, O. G. “Theory of Mechanisms and Machines”, Moscow: Nauka, 1984.

[8] Pavlishche, V. T., Kharchenko, Y. V., Barvinsky, A. F. et al. "Applied mechanics", Lviv: Intelect-Zakhid, 2004.

[9] Pogrebnyak, R. P. "Structural analysis and rational design parallelogram arm gripping", Metallurgy theory and practice 1-2, pp. $123-125, \quad$ 2015. DOI: 10.15802/stp2018/140547

[10] Reshetov, L. "Self-Aligning Mechanisms", Moscow: Mir Publishers, 1986.

[11] Segla, S. "Static balancing of robot mechanisms and manipulation devices", Strojnícky časopis - Journal of Mechanical Engineering 68 (2), pp. 77 - 90. 2018. DOI: 10.2478/scjme-2018-0019

[12] Shala A., Bruci. M. "Proposed robot scheme with 5 DOF and dynamic modelling using MAPLE software“, Strojnícky časopis - Journal of Mechanical Engineering 67 (2), pp. 101 - 108, 2017. DOI: $10.1515 /$ scjme-2017-0023

[13] Sydorenko, I., Kravtsov, E., Prokopovych, I. "Reducing the reliability of equipment as a result of the reduction of the culture of production", Proceedings of Odessa Polytechnic University 3 (59), pp. 5 - 13, 2019.

[14] Stepin, P. "Strength of Materials", New York: Gordon and Breach, 1963.

[15] Voinea, R., Atanasiu, M. "Contributions a la Teorie geometrique des Vis.", Buletinul Institutului Politichnic Bucuresti 21 (3), pp. 69 - 90, 1959.

[16] Zalyubovskii, M. G., Panasyuk, I. V. "On the Study of the Basic Design Parameters of a Seven-Link Spatial Mechanism of a Part Processing Machine”, Int. Appl. Mech. 56, pp. 54 - 64, 2020. DOI: 10.1007/s10778-020-00996-X

[17] Zdanevich, S. S., Pogrebnyak, R. P., Zdanevich, S. V. "Structural analysis and rational design of mechanisms of cross-roll tube straightening machines", Science and Transport 
Progress. Bulletin of Dnipropetrovs'k National University of Railway Transport. 5 (77), pp. 65 - 73, 2018. DOI: $10.15802 /$ stp2018/147630 